\title{
Engineered chromosome-based T7 RNA polymerase in Escherichia coli W3110 for orthogonal T7 promoter circuit as a cell factory
}

\section{Wan-Wen Ting}

National Cheng Kung University

Shih-I Tan

National Cheng Kung University

I-Son Ng ( yswu@mail.ncku.edu.tw)

National Cheng Kung University https://orcid.org/0000-0003-1659-5814

\section{Research}

Keywords: E. coli W3110, T7RNA polymerase, T7 promoter, recombinant protein, cadaverine

Posted Date: May 20th, 2020

DOI: https://doi.org/10.21203/rs.3.rs-29456/v1

License: (c) This work is licensed under a Creative Commons Attribution 4.0 International License.

Read Full License 


\section{Abstract \\ Background}

Orthogonal T7 RNA polymerase (T7RNAP) and T7 promoter were powerful tools to mediate the protein expression. Moreover, Escherichia coli W3110 strain possesses more advantages than the B strain due to more heat shock proteins and higher tolerance to chemicals. Therefore, implementation of T7-based system in W3110 strain is a conceivable strategy to develop the cell factory.

\section{Results}

Three novel W3110 strains with chromosome-equipped T7RNAP (i.e W3110:IL5, W3110::L5 and W3110::pl) were engineered to demonstrate the feasibility on protein expression and chemical production. At first, the LacZ and T7RNAP with IPTG induction showed higher expression levels in W3110 derivatives than that in BL21(DE3). The plasmids with and without lacl/lacO repression were used to investigate the protein expression of super-fold green fluorescence protein (sfGFP), Cas9, carbonic anhydrase (CA) and lysine decarboxylase (CadA). All the proteins were expressed higher and enzymatic functions were better in W3110::L5 and W3110::pl. Moreover, the highest cadaverine production, lysine consumption and the yield were obtained in W3110::L5(+) strain with pET28a(+)-CadA which reached $32.2 \mathrm{~g} / \mathrm{L}, 45 \mathrm{~g} / \mathrm{L}$ and $91.7 \%$ at $24 \mathrm{~h}$, while the W3110::pl(-) strain with pSU-T7-CadA achieved $36.9 \mathrm{~g} / \mathrm{L}$, $43.8 \mathrm{~g} / \mathrm{L}$ and $103.4 \%$ at $12 \mathrm{~h}$ which is unnecessary of inducer.

\section{Conclusion}

Inducer and $\mathrm{lacl} / \mathrm{lacO}$ regulators on chromosome and plasmid have been investigated in W3110 strains with T7RNAP. The newly engineered W3110::L5 and W3110:pl both possessed similar protein expression compared to commercial BL21(DE3). Furthermore, among all strains, W3110::pl displayed the greatest potential as cell factory in the future.

\section{Introduction}

It is indispensable to develop the recombinant technology which enables enhanced enzyme expression to endorse high value chemicals production in recent years. The recombinant technology inspired the scientific studies of enzymes, protein and protein interactions and the in vivo chemical production for industrial applications [1-3]. In addition, pharmaceutical and biotechnology companies applied recombinant technology to produce miscellaneous therapeutic proteins with the advantages of high output of the desired proteins and reduced cost due to the simplified purification processes. For example, recombinant insulin was the first practical therapeutic protein produced by $E$. coli and approved by the Food and Drug Administration [4]. Moreover, approximately 30\% recombinant proteins without 
glycosylation are produced from E. coli [5]. With different demands, more prokaryotic and eukaryotic chassis have been explored to produce recombinant therapeutic proteins.

Actually, E. coli has been widely used as a genetic strain due to the high growth rate, ease in culturing, well-characterized genome, and high availability of versatile genetic tools [6]. With the development of genetic tools and bioinformatics, it has been shown more possibilities to express foreign pathways and to produce valuable chemicals via manipulating the metabolic pathways in E. coli [7-9]. The cellular engineering in E. coli was originated from plasmid construction [10], followed by $\mathrm{pET}$ system for overexpression under orthogonal T7RNAP and promoter [11], homologous recombination [12], and also CRISPR/Cas9 technology for genome editing recently [13-16].

The E. coli B strain and derivatives lacking Lon and OmpT protease empowers producing heterologous proteins without protease attack. One such derivative, BL21(DE3), infected by $\lambda$ DE3 lysogen and exposed to the $T 7$ gene 1, possesses T7RNAP on the chromosome controlled by the $\mathrm{P}_{\text {LacUV5 }}$ promoter and the nearby lacl/lacO orthogonal regulator [11]. $\mathrm{P}_{\text {Lacuv } 5}$ is a mutant promoter of the native lac promoter, with a low sensitivity to glucose [17]. The expression is regulated by the lacl repressor, which binds to the lac operator ( $/ a c 0)$ in the absence of lactose. The repression can be removed by adding an inducer such as lactose or isopropyl- $\beta$-D-thiogalactopyranoside (IPTG) [18], resulting in target gene expression by the orthogonal T7 promoter. IPTG is frequently added to the T7 system due to its stability and effectiveness [19]; however, IPTG is expensive and uneconomic for industrial applications of low value-added products [20].

Alternatively, the K-12 strains such as MG1655 and W3110, are commonly used as they express more heat shock genes, are less sensitive to certain stress and also possess higher rates of glucose consumption [21-22]. A comparative proteomics study between BL21 and W3110 manifested that W3110 maintained growth and metabolism at lower oxygen levels, thus enabling foreign protein to be gradually expressed [23]. Therefore, W3110 strain has also been applied to produce various chemicals, including L-methionine [24-25], L-homoserine [26], and L-malate [27].

In this study, a powerful T7 system was equipped in W3110 strain to establish an alternative cell factory as a protein expression platform and microbial chemical production. First, T7RNAPs using different promoters, i.e., $\mathrm{P}_{\text {LacUV5 }}$ promoter with or without additional Lacl repressor and $\mathrm{P}_{\text {Lacl }}$ promoter, were inserted to the W3110 chromosome by a conditional replication, integration, and modular (CRIM) system [28] to develop three engineered W3110 strains. Then, the effect of lacl/lacO was explored by sfGFP as a proof-of-concept. To be a powerful cell factory, new engineered strains were applied to express Cas 9 for gene editing, carbonic anhydrase (CA) for capture of carbon dioxide and lysine decarboxylase CadA for production of cadaverine (DAP) as a precursor of bio-nylon materials. We attempted to explore the brighter opportunity of W3110 strain as a new platform to express heterologous protein and produce chemicals.

\section{Materials And Methods}




\section{Bacterial strains and culture conditions}

The bacterial strains used in this study are listed in Table 1. The E. coli DH5a was used for plasmid construction, and BL21(DE3) was applied for gene expression, while W3110 was engineered to equip with a chromosome-based T7RNAP by HKO22 phage attack site. All E. coli strains were cultivated in LuriaBertani (LB) medium at $37^{\circ} \mathrm{C}$ with constant shaking at $200 \mathrm{rpm}$. Antibiotics were added to the following final concentrations as needed: ampicillin $(100 \mu \mathrm{g} / \mathrm{mL})$, kanamycin $(50 \mu \mathrm{g} / \mathrm{mL})$, and chloramphenicol (25 $\mu \mathrm{g} / \mathrm{mL})$. 
Table 1

List of E. coli strains and plasmids used in this study

\section{Strains and Description plasmids}

Source or Accession number

\section{Strains}

W3110

$\mathrm{F}-, \lambda^{-}, I N(r r n D-r r n E) 1, r p h-1$

CGSC \#4474

BL21

$\mathrm{F}^{-}$ompT gal dcm lon hsd $S_{B}\left(r_{B}^{-} m_{B}^{-}\right)\left[m^{\prime} / B^{+}\right]_{K-12}\left(\lambda^{S}\right)$

NEB \#C2530H

BL21(DE3)

$\mathrm{F}^{-}$ompT gal dcm lon hsdS ${ }_{\mathrm{B}}\left(\mathrm{r}_{\mathrm{B}}{ }^{-} \mathrm{m}_{\mathrm{B}}{ }^{-}\right) \lambda(\mathrm{DE} 3$ [lacl lacUV5-

NEB \#C2527I

T7p07 ind1 sam7 nin5]) $\left[\mathrm{malB}^{+}\right]_{\mathrm{K}-12}\left(\lambda^{\mathrm{S}}\right)$

W3110::IL5

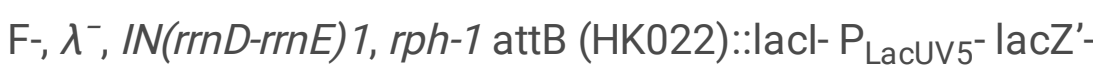

This study

T7 gene 1

W3110::L5

$\mathrm{F}-, \lambda^{-}, I N(r r n D-r r n E) 1, r p h-1$ attB (HK022):: $\mathrm{P}_{\text {LacUVV}^{-}}$lacZ'- T7

This study gene 1

W3110::pl

$\mathrm{F}-, \lambda^{-}, I N(r r n D-r r n E) 1, r p h-1$ attB (HK022):: $\mathrm{P}_{\text {Lacl }}$ T7 gene 1

This study

Plasmids

pAH69

4951 bp, Amp ${ }^{R}$, Rep101 ori, repA101(ts), HK022 integrase,

[28] clts857 protein

pHK-Km

2539 bp, Kan ${ }^{\mathrm{R}}$, R6K ori, FRT- HK022 attp- FRT

[29]

pDS3.0- HsdNC-

T7RNAP

11966 bp, Amp ${ }^{R}, G^{R}$, R6K ori, Hsd-N, $P_{\text {Lacl }}$ promoter, $T 7$ gene1, Hsd-R, sacB

pHK-IL5-Km

6933 bp, Kan ${ }^{R}$, R6K ori, FRT- HK022 attp- lacl-P Lacuv5 $^{-}$T7 promoter- lacZ'- T7 gene1- FRT

pHK-L5-Km

5766 bp, Kan ${ }^{\mathrm{R}}$, R6K ori, FRT- HK022 attp- $\mathrm{P}_{\text {Lacuv5- T7 }}$

This study

promoter- lacZ'- T7 gene1- FRT

pHK-pl-Km

6586 bp, Kan ${ }^{R}$, R6K ori, FRT- HK022 attp- Hsd-N- Pacl $_{\text {Lacl }}$

This study promoter- $T 7$ gene1- Hsd-R- FRT

pET28a (+)SfGFP

6013 bp, Kan ${ }^{\mathrm{R}}$, pBR322 ori, lacl, T7 promoter, lacO, sfGFP

This study

pSU-T7-sfGFP

9471 bp, $\mathrm{Cm}^{\mathrm{R}}$, pUC ori, T7 promoter, sfGFP

pSU-Placl-sfGFP

3099 bp, $\mathrm{Cm}^{\mathrm{R}}$, pUC ori, Placl promoter, sfGFP 


\begin{tabular}{|c|c|c|}
\hline $\begin{array}{l}\text { Strains and } \\
\text { plasmids }\end{array}$ & Description & $\begin{array}{l}\text { Source or } \\
\text { Accession } \\
\text { number }\end{array}$ \\
\hline $\begin{array}{l}\text { pSU-PlacUV5- } \\
\text { sfGFP }\end{array}$ & $3099 \mathrm{bp}, \mathrm{Cm}^{\mathrm{R}}, \mathrm{pUC}$ ori, PlacUV5 promoter, sfGFP & This study \\
\hline $\begin{array}{l}\text { pSU-PlacUV5- } \\
\text { NRBS-sfGFP }\end{array}$ & $3099 \mathrm{bp}, \mathrm{Cm}^{\mathrm{R}}, \mathrm{pUC}$ ori, PlacUV5 promoter, native RBS, sfGFP & This study \\
\hline $\begin{array}{l}\text { pSU-PlacUV5- } \\
\text { LacZa'-sfGFP }\end{array}$ & 3571 bp, $\mathrm{Cm}^{\mathrm{R}}$, pUC ori, PlacUV5 promoter, LacZa', sfGFP & This study \\
\hline pET32a-SyCA & $\begin{array}{l}6595 \text { bp, Amp }{ }^{\mathrm{R}} \text {, pBR322 ori, trxA, lacl, T7 promoter, lacO, } \\
\text { SyCA }\end{array}$ & [32] \\
\hline $\begin{array}{l}\text { pET21a (+)- } \\
\text { Cas9 }\end{array}$ & $\begin{array}{l}9471 \text { bp, Amp }{ }^{\mathrm{R}} \text {, pBR322 ori, lacl, T7 promoter, lacO, SpCas9- } \\
\text { 6His }\end{array}$ & Lab stock \\
\hline $\begin{array}{l}\text { pET20b (+)- } \\
\text { Cas9 }\end{array}$ & 7694 bp, Amp ${ }^{\mathrm{R}}$, pBR322 ori, ROP, T7 promoter, Spcas9-6 His & This study \\
\hline $\begin{array}{l}\text { pET28a }(+)- \\
\text { CadA }\end{array}$ & 7498 bp, Kan ${ }^{\mathrm{R}}, \mathrm{pBR} 322$ ori, lacl, T7 promoter, lacO, cadA & This study \\
\hline pSU-T7-CadA & $4255 \mathrm{bp}, \mathrm{Cm}^{\mathrm{R}}$, pUC ori, T7 promoter, cadA & This study \\
\hline
\end{tabular}

\section{Construction Of CRIM Plasmids With T7RNAP Under Different Promoters}

The pHK plasmid was used for inserting an integrated fragment including the HKO22 attP, FRT, and multiple cloning sites [29]. The first CRIM plasmid, pHK-IL5T7-Km, was designed to create a strain that imitates BL21(DE3), constructed by polymerase chain reaction (PCR) of the BL21(DE3) genome with primers EcoRI-lacl-F and Pstl-T7P-R and digested with EcoRI and Pstl, cloned into the pHK-Km backbone. The pHK-L5T7-Km was constructed by PCR from pHK-IL5T7-Km with primers EcoRI-P lacUv5 5 F and PstlT7P-R, while plasmid of pHK-pIT7-Km was cloned by PCR from pDS3.0-HsdNC-T7RNAP with primers EcoRI-Placl-T7P-F and Pstl-Placl-T7P-R to obtain T7RNAP under different promoters. The primers used are listed in Table $\mathrm{S} 1$.

\section{Engineered Chromosome-based T7RNAP In W3110}

Site-specific recombination was applied to integrate T7RNAP into the W3110 genome. This process requires the CRIM plasmid as mentioned above, which includes an attP phage attachment site complementary to the attB phage attachment site on the genome, and a helper plasmid that includes integrase [28]. The helper plasmid pAH69 was transformed into the host strain at first. To prepare competent cells, a transformant cultivated at $30{ }^{\circ} \mathrm{C}$ until the $\mathrm{OD}_{600}$ reached 0.3 ; the temperature then 
increased to $39^{\circ} \mathrm{C}$ for 30 min to induce integrase production. The heat-shock transformation was used to transfer the CRIM plasmid into the host strain, followed by recovery at $37^{\circ} \mathrm{C}$ for $2-3 \mathrm{~h}$. Afterwards, positive colonies were screened on LB agar medium with $17 \mu \mathrm{g} / \mathrm{mL}$ kanamycin at $37^{\circ} \mathrm{C}$ to check the removal of the PAH69. To construct marker-free strains, PCP20 plasmid was further transformed to remove the resistance fragment flanked by FRT sites by FLP recombinase. One colony was randomly selected and pre-cultured in LB with antibiotic at $30^{\circ} \mathrm{C}$. The cells were inoculated in LB broth without antibiotic and cultured at $37^{\circ} \mathrm{C}$ for $6-8 \mathrm{~h}$, followed by transferring to $39^{\circ} \mathrm{C}$ for $1 \mathrm{~h}$. The cells were then diluted and spread on an LB plate at $37^{\circ} \mathrm{C}$. After overnight cultivating, the colonies were screened on selective plates.

\section{Construction Of Expression Vectors}

The pET28a(+)-sfGFP plasmid was constructed by amplifying the sfGFP fragment from pSU-placl-sfGFP with primers Ndel-sfGFP-F and Xhol-sfGFP-R, followed by digestion with $N d e l$ and $X h o l$ and cloning into pET28a(+)-RFP, which was digested with the same digestion enzymes in advance. The pET20b(+)-Cas9 was constructed by digestion with $X b a l$ and $X h o l$ from pET21a(+)-Cas 9 to obtain the cas 9 fragment. The fragment was cloned into pET2Ob(+), which was digested by $X$ bal and $X h o l$ in advance. The cadA fragment was amplified with HindIII-CadA-F and Bgll-CadA-R from E. coli MG1655, digested with HindII and $B g h l$, and inserted into the pSU-T7 backbone, creating the pSU-T7-CadA plasmid. The PSU-P LacUV5 $^{-}$ sfGFP was constructed by replaced the promoter of pSU-T7-sfGFP and the fragment of $\mathrm{P}_{\text {LacUV5 }}$ was amplified from pHK-L5-Km with primers Xbal-L5-F and BamHI-L5-R. The PCR fragment was digested with $X$ bal and BamHI and cloned into pSU-T7-sfGFP. The pSU-P LacUV5 $_{5}$-NRBS-sfGFP was constructed by replaced the promoter and RBS of pSU-T7-sfGFP. The inserted fragment was amplified with primers $X b a l-$ L5-F and HindIII-L5-R from pHK-L5-Km, further digested with Xbal and HindIII and cloned into pSU-T7sfGFP. The pSU-P LacUV5 -LacZa'-sfGFP was constructed by inserted the fragment of $P_{\text {LacUV }}$-LacZa' into the backbone of pSU-T7-sfGFP. The inserted fragment was amplified with Xbal-L5-F and HindIII-L5Z-R from pHK-L5-Km. All the plasmids are shown in Table 1.

\section{Culture And Induction}

For sfGFP protein and fluorescence analysis, the samples were inoculated with $2 \%(\mathrm{v} / \mathrm{v})$ pre-culture broth in 10-mL glass cultivation tubes and cultivated in a $37^{\circ} \mathrm{C}$ incubator. IPTG was added to a final concentration of $0.1 \mathrm{mM}$. For protein analysis of Cas9, the samples were inoculated with $2 \%(\mathrm{~V} / \mathrm{v})$ preculture broth in a 100-mL flask with $10 \mathrm{~mL} \mathrm{LB}$ broth, and the desired antibiotic was added. When the cell density achieved an $\mathrm{OD}_{600}$ of 0.5 to 0.8 , IPTG was added, and transfer to cultivate in a $22^{\circ} \mathrm{C}$ incubator for $12 \mathrm{~h}$. The cultivation for the activity measurement of SyCA, $20 \mathrm{~mL}$ LB broth was inoculated with $2 \%(\mathrm{v} / \mathrm{v})$ pre-culture broth in a $100-\mathrm{mL}$ flask. As $\mathrm{OD}_{600}$ reached 0.6 to 0.8 , IPTG was added at three different concentrations of $0.005,0.01$ and $0.1 \mathrm{mM}$, and $0.5 \mathrm{mM}$ zinc ions (supplied by $\mathrm{ZnSO}_{4}$ ) were also added. Further keep cultivating at $37^{\circ} \mathrm{C}$ until $12 \mathrm{~h}$. For the protein analysis of CadA, $100-\mathrm{mL}$ flask with $10 \mathrm{~mL}$ LB 
broth was inoculated with $2 \%(\mathrm{v} / \mathrm{v})$ pre-culture cell, when $\mathrm{OD}_{600}$ reached 0.6 to 0.8 , IPTG was added from $0,10^{-5}, 10^{-4}, 10^{-2}, 10^{-3}$ to $0.1 \mathrm{mM}$ for pET28a(+)-CadA and $0.1 \mathrm{mM}$ for pSU-T7-CadA.

\section{Measurement Of Cell Growth And Fluorescence Intensity}

The cell growth was monitored by absorbance at $600 \mathrm{~nm}\left(\mathrm{OD}_{600}\right)$ and the fluorescence intensity was detected by a SpectraMax M2 microreader (Molecular Device, USA) with excitation at $480 \mathrm{~nm}$ and emission at $510 \mathrm{~nm}$. All experiments were performed in triplicates.

\section{Protein Expression, Quantification And Identification Analysis}

The recombinant protein expression was analyzed by $8 \%, 10 \%$ or $12 \%$ sodium dodecyl sulfate polyacrylamide gel electrophoresis (SDS-PAGE). After a 12-h culture, the cells were harvested by centrifugation $(12000 \times \mathrm{g}, 3 \mathrm{~min})$. The cell concentration was adjusted to OD 4 , and the cells were suspended in $\mathrm{dH}_{2} \mathrm{O}$. The supernatant and cell debris were separated by centrifugation after the whole cells were degraded by a One Shot instrument (Constant Systems, UK). 1D electrophoretic protein separation was achieved by following a standard SDS-PAGE protocol ( $80 \mathrm{~V}, 30 \mathrm{~min} ; 120 \mathrm{~V}, 70 \mathrm{~min})$. Afterwards, the gel was stained with Coomassie brilliant blue G-250 dye for visualization. ImageLab® (Bio-rad) adopted from a Gaussian model was used in finding differentially expressed proteins of SDSPAGE [30]. The target protein was sent for LC-Q-TOF mass spectrometer (Applied Biosystems, Lincoln, CA). Injected samples were first trapped and desalted on an LC-Packings PepMap ${ }^{\mathrm{TM}} \mathrm{C} 18 \mu$-Precolumn ${ }^{\mathrm{TM}}$ Cartridge $(5 \mu \mathrm{m}, 5 \mathrm{~mm} \times 30 \mu \mathrm{m}$ I.D.; Dionex, Sunnyvale, CA). Subsequently, peptides were eluted from the pre-column and separated on an analytical LC-Packings PepMap C18 column (3 $\mu \mathrm{m}, 15 \mathrm{~cm} \times 75 \mu \mathrm{m}$ I.D. $)$ connected in-line to the mass spectrometer, at a flow rate of $200 \mathrm{~nL} / \mathrm{min}$ using a 40 -min gradient of 5 to $60 \%$ acetonitrile in $0.1 \%$ formic acid. Only significant hits from the individual MS/MS spectra were considered by mascot probability analysis.

In vitro assay of Cas9-ribonucleoprotein (Cas9-RNP)

Double-stranded DNA sgRNA was synthesized via overlap PCR to combine the crRNA fragments and the scaffold. The sgRNA was synthesized by in vitro transcription with double-stranded DNA sgRNA as the template, 10x transcription buffer, rNTP solution mixture, and T7 RNA polymerase. The crude sgRNA was purified by the phenol-chloroform method. Crude Cas9 protein was purified by His-trap metal-ion affinity chromatography with an $\mathrm{AKTA}^{\mathrm{TM}}$ start machine (GE Healthcare, UK). Imidazole was removed from the purified Cas9 protein by Amicon ${ }^{\circledR} 100-k D a$ ultrafiltration (Merck, USA). The Cas9-RNP was formed by mixing equal molar ratios of purified Cas 9 and sgRNA in $5 x$ reaction buffer $(100 \mathrm{mM} \mathrm{HEPES,} \mathrm{pH} \mathrm{7.5,}$ $500 \mathrm{mM} \mathrm{KCl}, 25 \%$ glycerol, $5 \mathrm{mM} \mathrm{DTT}, 2.5 \mathrm{mM}$ EDTA, $10 \mathrm{mM} \mathrm{MgCl}_{2}$ at pH 8.0) at room temperature for $15 \mathrm{~min}$. In vitro digestion was achieved by adding 100 to $200 \mathrm{ng}$ DNA template at $37^{\circ} \mathrm{C}$ for $1 \mathrm{~h}$. 


\section{Determination of CA activity by Wilbur-Anderson unit (WAU)}

The cell expressing the CA was collected and washed 3 times by deionized water and finally adjusted to OD 5 for further use. The CA activity was determined by Wilbur-Anderson Assay as our previous publication. Briefly, $9 \mathrm{~mL}$ ice-cold Tris- $\mathrm{HCl}(20 \mathrm{mM}$, pH8.3) buffer and $0.2 \mathrm{~mL}$ enzyme were mixed and put in a $20 \mathrm{~mL}$ sample bottle at $0^{\circ} \mathrm{C}$ under stirring. Then, $6 \mathrm{~mL}$ ice-cold $\mathrm{CO}_{2}$-saturated solution was added into sample bottle immediately. The time in second that $\mathrm{pH}$ value dropped down from 8.3 to 6.3 was recorded and the CA activity was calculated by a Wilbur-Anderson unit (WAU) per milliliter of sample. The definition for WAU is $\left(T_{0}-T\right) / T$, which $T_{0}$ and $T$ is the time from $\mathrm{pH} 8.3$ to 6.3 without and with CA.

In vivo cadaverine production

A $2 \%(\mathrm{~V} / \mathrm{V})$ pre-culture was inoculated in a $100-\mathrm{mL}$ flask and cultivated in a $37^{\circ} \mathrm{C}$ incubator. When the $\mathrm{OD}_{600}$ reached $0.5-0.8,0.1 \mathrm{mM} \mathrm{IPTG}$ was added as an inducer, with $0.35 \mathrm{M}$ lysine and $0.01 \mathrm{mM}$ pyridoxal phosphate (PLP) as the substrate and co-factor, respectively. The growth, lysine conversion, and cadaverine production were measured every $6 \mathrm{~h}$.

\section{Derivatization And High-performance Liquid Chromatography (HPLC)}

Lysine and cadaverine derivatives were obtained by combining $340 \mu \mathrm{L} 50 \mathrm{mM}$ borate buffer (pH 9), 240 $\mu \mathrm{L} 100 \%$ methanol, $12 \mu \mathrm{L} 200 \mathrm{mM}$ diethyl ethoxymethylenemalonate (DEEMM) without pretreatment, and $6 \mu \mathrm{L}$ of the sample $(<0.1 \mathrm{M})$. The mixture was heated in a $70^{\circ} \mathrm{C}$ water bath for $2 \mathrm{~h}$ to allow complete degradation of excess DEEMM and derivatization [31]. After derivatization with DEEMM, HPLC was performed with a binary pump, in-line degasser, auto-sampler, and column thermostat. Chromatographic separation was conducted by reverse-phase chromatography on a C18 column (YMC-C18 column, 4.6 $\times$ $250 \mathrm{~mm}, 5-\mathrm{mm}$ particle size) maintained at $35^{\circ} \mathrm{C}$. Mobile phases $A$ and $B$ were composed of $25 \mathrm{mM}$ sodium acetate and $100 \%$ acetonitrile, respectively. A flow rate of $0.8 \mathrm{~mL} / \mathrm{min}$ was used, with the following gradient program: $0-2 \mathrm{~min}, 80-75 \% \mathrm{~A} ; 2-30 \mathrm{~min}, 75-40 \% \mathrm{~A} ; 30-35 \mathrm{~min}, 40-80 \% \mathrm{~A}$. The UV detector operated at a wavelength of $284 \mathrm{~nm}$.

\section{Results}

\section{Engineered E. coli W3110 equipped with T7RNAP}

Three different designs of T7RNAP cassettes were constructed and integrated into the W3110 chromosome by traditional site-specific recombination at the attB sites of lambdoid coliphage HKO22 (Fig. 1a). The first strain, denoted as W3110::IL5 and similar to BL21(DE3), contained a T7 gene 1 driven by $\mathrm{P}_{\mathrm{LaCUV}} 5$ with $/ \mathrm{acl} / \mathrm{lacO}$ and an additional lacl genes located upstream of the promoter. Second strain was W3110::L5, in which additional lacl at upstream of the $\mathrm{P}_{\text {LacUV5 }}$ promoter was not presented. The third 
strain, W3110::pl, was significantly different from the previous two strains because the $T 7$ gene 1 was driven by $P_{\text {Lacl, }}$ which is widely used in iGEM (https://parts.igem.org/Part:BBa_R0010) (see detail sequence in Table S2). The newly created strains were verified by amplifying a characteristic fragment in each strain (Fig. 1b), and the results showed that all strains were successfully constructed.

The cell growth (Fig. 2a), LacZ and T7RNAP protein expressions (Fig. 2b) were compared among three engineered W3110 strains equipped with the T7RNAP. The biomass at the log-phase was slightly different between the condition with or without IPTG induction, while, at $12 \mathrm{~h}$, the biomass was similar at the OD ranging from 2.2 to 2.5. Furthermore, to confirm the protein expression, SDS-PAGE was performed (Fig. 2b) and showed there were two distinct bands as comparing between the condition with or without IPTG. The identity of distinct proteins was detected by LC-MS/MS and shown in the Table 2, where a band near $100 \mathrm{kDa}$ corresponded to T7RNAP, and the band between 100 to $135 \mathrm{kDa}$ was identified as LacZ. Besides, the quantification was performed based on the ImageLab and shown in Table 3. Interestingly, LacZ expression was much higher in the W3110 than that in BL21(DE3) (Fig. 2b and Fig. S1). The enhancements were observed as 2.63-fold for W3110, 3.41-fold for W3110::IL5, 5.21-fold for W3110::L5, and 4.61-fold for W3110::pl (Table 3). Furthermore, the T7RNAP expression also reached up to 8.72-fold for W3110::IL5, 6.72-fold for W3110::L5 and 11.92-fold for W3110::pl, implying the promoters of $P_{\text {LacUV5 }}$ was stronger in W3110 than that in BL21(DE3) and the $P_{\text {Lacl }}$ even the strongest promoter in W3110. Except for the promoter effect, the inserted locus was supposed to be the reason that T7RNAP expression was extremely higher than that in BL21(DE3) because the locus was at HKO22 attB site in engineered W3110 strains from 1053856-1057711 bp, while that of BL21(DE3) was around the lac operon site (i.e., 360473-365652 bp) (Fig. 1a). With IPTG induction, maximum T7RNAP was observed in W3110::pl while the lowest one was occurred in the W3110::L5 (Table 3, T7RNAP). The feasibility of three strains used in protein expression and chemical production was further verified in the following.

Table 2

MS/MS analysis of T7 RNA polymerase and lacZ gene from engineered E. coli W3110.

\begin{tabular}{|llllll|}
\hline No. & Protein & Accession no. & Score & $\begin{array}{l}\text { Molecular weight } \\
(\mathrm{Mw}, \mathrm{Da})\end{array}$ & $\begin{array}{l}\text { Isoelectric point } \\
\text { (pl) }\end{array}$ \\
\hline 1 & $\begin{array}{l}\text { T7-like RNA } \\
\text { polymerase }\end{array}$ & WP_001092355 & 955 & 98.79 & 6.77 \\
\hline 2 & $\begin{array}{l}\text { LacZ } \\
\text { beta-galactosidase }\end{array}$ & WP_096183704 & 1036 & 116.42 & 5.28 \\
\hline
\end{tabular}


Table 3

Quantification of relative protein of LacZ and T7RNAP by IPTG induction in BL21(DE3), W3110, W3110::IL5, W3110::L5, W3110::pl.

\begin{tabular}{|llllll|}
\hline Relative protein amounts & BL21(DE3)* & W3110 & W3110::IL5 & W3110::L5 & W3110::pl \\
\hline LacZ & 1.0 & 2.63 & 3.41 & 5.21 & 4.61 \\
\hline T7RNAP & 1.0 & - & 8.72 & 6.72 & 11.92 \\
\hline *LacZ and T7RNAP in BL21(DE3) with IPTG is defined as the reference of W derivatives. \\
\hline
\end{tabular}

Demonstrate lacl/lac0 regulation in the new strains by sfGFP

Two expression vectors, the pET28a(+) plasmid with the orthogonal lacl/laco repressor (Fig. 3a) and the pSU-T7 plasmid without repressor were used for evaluation (Fig. 3b). At first, lacl was included in the system to verify the lacl/lacO effect of engineered strains. As shown in Fig. 3c, there was no obvious florescence intensity in all strains without IPTG. Besides, when IPTG was induced, it displayed the similar level of sfGFP protein with the average fluorescence of 47,000 a.u. in three engineered W3110 strains, but lower expression in BL21(DE3) (i.e. 31000 a.u.). The sfGFP expression by the pSU-T7-sfGFP plasmid which lacked of $/ a c l / l a c 0$, the highest fluorescence intensity of 18,000 a.u. in W3110::pl without IPTG and the similar florescence intensity at 11,000 a.u. was observed in other strains (Fig. 3d). Interestingly, when IPTG was added, the specific fluorescence intensity of W3110::L5 was the highest with enhancement of $46 \%, 75 \%$ and $77 \%$ as compared to the BL21(DE3), W3110::IL5 and W3110::pl, respectively (Fig. $3 d$ ). As a result, lacl/ lacO was the key component to regulate protein expression in W strains under IPTG induction.

\section{Cas9 Expression And Characterization In Engineered W3110}

Cas9 is a heterologous toxic protein derived from Streptococcus pyogenes and plays an important role in the type II CRISPR/Cas system. Two pET systems were used to express Cas9 protein: the pET21a(+) system, which includes an orthogonal lacl/lacO repressor (Fig. 4a), and the pET20b(+) system, which lacked both sequences (Fig. 4b). The protein analysis results for pET21a(+)-Cas9 showed that the protein was only produced in the presence of an inducer, and the order of protein content was BL21(DE3) W3110::pl > W3110::L5 > W3110::IL5 (Fig. 4c). For pET20b(+)-Cas9, when the IPTG was absent, there were equal levels of protein expression in BL21(DE3), W3110::IL5, and W3110::L5, while that in W3110::pl was 2 -fold higher than other three strains. After IPTG induction, the protein expression was increased or kept at similar level in all strains except for W3110::IL5. Among all combination of strains and conditions, W3110::pl with or without IPTG produced highest Cas9 protein, similar to those of BL21(DE3) and W3110::L5 with induction, (Fig. 4d).

To evaluate the functionality of the Cas9 protein produced from our engineered W3110 strain, an in vitro Cas9-RNP assay was applied. Ribulose-1,5-bisphosphate carboxylase/oxygenase (RuBisCO, $r b c L$ ) was 
selected as our targeted template (i.e. $1.5 \mathrm{k}$ ) for digestion and the sgRNA was designed to slice the DNA into two fragments (i.e. $0.6 \mathrm{k}$ and $0.9 \mathrm{k}$ ). The results of in vitro cleavage showed that the $r b c \mathrm{~L}$ fragment was successfully divided into two desired fragments (Fig. 4e), demonstrating that all three engineered strains produced functional Cas9 successfully.

\section{Carbonic Anhydrase Expression And Activity In Engineered W3110 Strains}

In our previous report, BL21(DE3) overexpressing carbonic anhydrase (CA) showed the arrested cell growth as compared to that without CA expression [32]. Therefore, we considered whether W3110 strain would tolerate CA overexpression via pET32a-SyCA. At first, the result of biomass in BL21(DE3) has 30\% reduction at $12 \mathrm{~h}$ which showed the toxicity to the cell; however, newly engineered W3110 could tolerate to the CA more robustly because the reduced biomass was only $25 \%, 2 \%$ and $18 \%$ for W3110::IL5, W3110::L5 and W3110::pl, respectively (Fig. 5a). Due to lacl/ lacO regulation in the plasmid, IPTG induction was required for CA production. The CA activity was shown in Fig. 5b. In BL21(DE3), the CA activity increased from 803 WAU to 1100 WAU as IPTG increased from $0.005 \mathrm{mM}$ to $0.01 \mathrm{mM}$ and kept the similar level with $0.1 \mathrm{mM}$ IPTG. The CA activity of W3110:IL5 was 1400 WAU with $0.005 \mathrm{mM} \mathrm{IPTG}$ and sharply decreased to 400 WAU at that with 0.1 mM IPTG. However, the W3110::L5 and W3110:pl expressed highest CA activity with 1710 WAU at $0.01 \mathrm{mM} \mathrm{IPTG}$ and 1795 WAU at 0.005 and $0.01 \mathrm{mM}$ IPTG, respectively. Therefore, the best strain for production of CA is W3110::pl because it maintains the biomass and possesses the highest CA activity with extremely low IPTG.

\section{Conversion of lysine to cadaverine by the engineered W3110 strains}

It has been reported that the W3110 strain could tolerant to $20 \mathrm{~g} / \mathrm{L}$ diaminopentane (DAP) [33]. Herein, the DAP toxicity test was performed in 4 strains by the ratio of viable cell which defined as the ratio of biomass between DAP addition and without addition. It showed that the cell would dramatically reduce after the DAP of $10 \mathrm{~g} / \mathrm{L}$ was added, but W3110 possess higher survival rate than BL21(DE3), in which the viable cell percent was $32.1 \%, 34.0 \%, 42.8 \%$ and $36.6 \%$ for BL21(DE3), W3110:IL5, W3110::L5 and W3110::pl (Fig. S2). Afterwards, two CadA-containing plasmids with or without lacl/lacO (i.e. pET28a(+)CadA and pSU-T7-CadA) were transformed into four strains and the in vivo DAP production was conducted to verify the function of lysine decarboxylase.

The IPTG concentration was varied in the four strains harboring pET28a(+)-CadA (Fig. 6). Similar levels of CadA proteins were observed for BL21(DE3), W3110::L5 and W3110::pl, in which the CadA was expressed at IPTG concentrations from 0.1 to $0.01 \mathrm{mM}$. More CadA was expressed with $0.1 \mathrm{mM}$ IPTG than that with 0.01 mM IPTG in BL21(DE3) (Fig. 6b). However, CadA in W3110::IL5 was only overexpressed with $0.1 \mathrm{mM}$ IPTG, and expressed with a critical low amount of protein by $0.01 \mathrm{mM}$ IPTG (Fig. 6c). Furthermore, CadA could be expressed in a critical low IPTG (i.e., $0.001 \mathrm{mM}$ ) in W3110::L5 (Fig. 6d), and the highest expression occurred in W3110::pl with 0.01 mM IPTG (Fig. 6e). For the in vivo 
lysine production, lysine, IPTG, and PLP were added at $0.35 \mathrm{M}, 0.1 \mathrm{mM}$, and $0.01 \mathrm{mM}$ during the initial exponential phase (i.e., $3 \mathrm{~h}$ ). All the strain possessed highest DAP production at $24 \mathrm{~h}$ as pET28a(+)-CadA was used. The highest lysine consumption for in BL21(DE3)(+) and W3110::IL5(+) was only $21.6 \mathrm{~g} / \mathrm{L}$ and $18.13 \mathrm{~g} / \mathrm{L}$, respectively. However, the lysine could be more efficiently utilized in the W3110::L5 and W3110::pl with a $45 \mathrm{~g} / \mathrm{L}$ and $32.41 \mathrm{~g} / \mathrm{L}$ consumption of lysine. Therefore, the highest DAP production were obtained from W3110::L5(+) with $45.01 \mathrm{~g} / \mathrm{L}$ lysine consumption, $32.2 \mathrm{~g} / \mathrm{L}$ DAP, $1.34 \mathrm{~g}-\mathrm{DAP} / \mathrm{L} / \mathrm{h}$ productivity and $91.73 \%$ yield at $24 \mathrm{~h}$ (Table 4 ).

Table 4

Biomass, lysine consumption, DAP titer, DAP productivity, yield of in vivo time-course with pET28a(+)CadA plasmid and $50 \mathrm{~g} / \mathrm{L}$ lysine in BL21(DE3), W3110::IL5, W3110::L5 and W3110::pl, respectively.

\begin{tabular}{|c|c|c|c|c|c|}
\hline Strain* & $\begin{array}{l}\text { Time } \\
\text { (h) }\end{array}$ & Lysine consumption (g/L) & $\begin{array}{l}\text { DAP Titer } \\
(\mathrm{g} / \mathrm{L})\end{array}$ & $\begin{array}{l}\text { Productivity } \\
\text { (g-DAP/L/h) }\end{array}$ & $\begin{array}{l}\text { Yield } \\
(\mathrm{g} / \mathrm{g}, \%)\end{array}$ \\
\hline \multirow[t]{3}{*}{ BL21(DE3)(+) } & 6 & $9.07 \pm 1.5$ & $2.5 \pm 0.1$ & $0.42 \pm 0.07$ & $6.78 \pm 1.17$ \\
\hline & 12 & $9.40 \pm 1.7$ & $5.2 \pm 1.0$ & $0.43 \pm 0.08$ & $13.80 \pm 2.50$ \\
\hline & 24 & $21.60 \pm 1.4$ & $11.3 \pm 1.3$ & $0.47 \pm 0.06$ & $30.05 \pm 3.95$ \\
\hline \multirow[t]{3}{*}{ W3110::IL5(+) } & 6 & $9.14 \pm 2.4$ & $4.0 \pm 1.5$ & $0.67 \pm 0.25$ & $11.59 \pm 2.09$ \\
\hline & 12 & $16.67 \pm 3.7$ & $10.4 \pm 1.9$ & $0.87 \pm 0.16$ & $29.38 \pm 1.80$ \\
\hline & 24 & $18.13 \pm 0.3$ & $13.6 \pm 1.6$ & $0.57 \pm 0.07$ & $38.12 \pm 5.89$ \\
\hline \multirow[t]{3}{*}{ W3110::L5(+) } & 6 & $17.13 \pm 1.8$ & $11.8 \pm 0.1$ & $1.97 \pm 0.02$ & $33.62 \pm 4.45$ \\
\hline & 12 & $40.90 \pm 2.8$ & $29.0 \pm 2.0$ & $2.42 \pm 0.16$ & $82.46 \pm 7.62$ \\
\hline & 24 & $45.01 \pm 1.2$ & $32.2 \pm 0.2$ & $1.34 \pm 0.01$ & $91.73 \pm 8.07$ \\
\hline \multirow[t]{3}{*}{ W3110::pl (+) } & 6 & $14.50 \pm 3.7$ & $10.12 \pm 1.1$ & $1.69 \pm 0.18$ & $29.05 \pm 2.51$ \\
\hline & 12 & $28.45 \pm 3.0$ & $19.85 \pm 2.1$ & $1.65 \pm 0.17$ & $56.96 \pm 3.05$ \\
\hline & 24 & $32.41 \pm 2.0$ & $22.61 \pm 2.4$ & $0.94 \pm 0.10$ & $64.89 \pm 1.01$ \\
\hline
\end{tabular}

The protein expression in pSU-T7-CadA without lacl/lacO (Fig. 6f) was analyzed in four different strains. The results were similar to the Cas9 protein results, except for W3110::IL5; in addition, the leakage was lower in W3110::L5 than in BL21(DE3) and W3110::IL5 (Fig. 6g). The CadA expressions in W3110::pI(-) and $(+)$ are similar, which indicated constitutive $P_{\text {Lacl }}$ promoter was effective. For the pSU-T7-CadAharbored strains as shown in Table 5 , in vivo production of DAP by lysine consumption of all strains (except for W3110::IL5) reached $80 \%$ yield at $12 \mathrm{~h}$, while DAP yield decreased until $24 \mathrm{~h}$, mainly due to DAP would be further utilized in the metabolic pathway. The best condition was used W3110::pl(-) to obtain 36.9 g/L DAP, 3.08 g-DAP/L/h productivity and 103.4\% yield by pSU-T7-CadA. We found out that it 
is reasonable that the yield value was higher than $100 \%$. Because the lysine concentration in LB medium was approximately $1.61 \mathrm{~g} / \mathrm{L}$ by HPLC analysis from the retention time (Fig S3a) and calibration curve (Fig. S3b). As comparing the results between pSU-T7-CadA and pET28a(+)-CadA, a significant enhancement in the lysine consumption rate existed by pSU-T7-CadA. The strains harboring the pSU-T7CadA consumed up to 41.59, 37.35, 41.98 and $42.09 \mathrm{~g} / \mathrm{L}$ lysine for BL21(DE3)(+), W3110::IL5(+), W3110::L5(+) and W3110::pl(+) at $24 \mathrm{~h}$, while the lysine consumption of strains harboring the pET28(+)CadA was only $21.6,18.13,45.01$ and $32.41 \mathrm{~g} /$ in the same strains. This manifested a more feasible strategy to apply the constitutive system (i.e. without the lacl/lacO regulation) in W3110 for chemical production due to higher chemical production rate and precursor consumption rate.

Table 5

Biomass, lysine consumption, DAP titer, DAP productivity, yield of in vivo time-course with pSU-T7-CadA plasmid and $50 \mathrm{~g} / \mathrm{L}$ lysine in BL21(DE3), W3110::IL5, W3110::L5 and W3110::pl, respectively.

\begin{tabular}{|c|c|c|c|c|c|}
\hline Strain & Time (h) & Lysine consumption (g/L) & $\begin{array}{l}\text { DAP Titer } \\
(\mathrm{g} / \mathrm{L})\end{array}$ & $\begin{array}{l}\text { Productivity } \\
\text { (g DAP/L/h) }\end{array}$ & $\begin{array}{l}\text { Yield } \\
(\mathrm{g} / \mathrm{g}, \%)\end{array}$ \\
\hline \multirow[t]{3}{*}{ BL21(DE3)(+) } & 6 & $24.21 \pm 1.3$ & $18.3 \pm 1.2$ & $3.05 \pm 0.05$ & $51.3 \pm 1.2$ \\
\hline & 12 & $38.94 \pm 2.2$ & $32.4 \pm 2.5$ & $2.70 \pm 0.02$ & $90.7 \pm 3.2$ \\
\hline & 24 & $41.59 \pm 1.9$ & $28.0 \pm 1.5$ & $1.17 \pm 0.01$ & $78.4 \pm 4.3$ \\
\hline \multirow[t]{3}{*}{ W3110::IL5(+) } & 6 & $16.56 \pm 0.6$ & $12.8 \pm 0.5$ & $2.13 \pm 0.03$ & $35.9 \pm 2.9$ \\
\hline & 12 & $31.14 \pm 1.1$ & $22.4 \pm 1.1$ & $2.60 \pm 0.04$ & $62.7 \pm 1.6$ \\
\hline & 24 & $37.35 \pm 1.6$ & $23.9 \pm 0.9$ & $1.00 \pm 0.01$ & $66.9 \pm 1.8$ \\
\hline \multirow[t]{3}{*}{ W3110::L5(+) } & 6 & $19.92 \pm 1.0$ & $15.4 \pm 0.3$ & $2.56 \pm 0.02$ & $43.1 \pm 1.9$ \\
\hline & 12 & $37.50 \pm 2.4$ & $29.3 \pm 0.5$ & $2.44 \pm 0.05$ & $82.1 \pm 1.7$ \\
\hline & 24 & $41.98 \pm 1.4$ & $24.9 \pm 0.8$ & $1.04 \pm 0.01$ & $69.7 \pm 12.5$ \\
\hline \multirow[t]{3}{*}{ W3110::pl (+) } & 6 & $32.51 \pm 1.1$ & $25.4 \pm 1.6$ & $4.24 \pm 0.07$ & $71.1 \pm 3.2$ \\
\hline & 12 & $40.22 \pm 1.7$ & $31.9 \pm 2.0$ & $2.66 \pm 0.05$ & $89.4 \pm 3.5$ \\
\hline & 24 & $42.09 \pm 1.9$ & $26.3 \pm 1.9$ & $1.10 \pm 0.02$ & $73.7 \pm 4.2$ \\
\hline \multirow[t]{3}{*}{ W3110::pl (-) } & 6 & $41.25 \pm 1.1$ & $36.7 \pm 2.0$ & $6.11 \pm 0.11$ & $102.8 \pm 2.7$ \\
\hline & 12 & $43.85 \pm 1.5$ & $36.9 \pm 1.3$ & $3.08 \pm 0.09$ & $103.4 \pm 3.0$ \\
\hline & 24 & $44.69 \pm 0.9$ & $31.4 \pm 2.8$ & $1.31 \pm 0.02$ & $88.0 \pm 2.2$ \\
\hline
\end{tabular}

*(+) means with IPTG induction; (-) means without IPTG induction. The errors represent the standard derivation of 3 independent experiments $(n=3)$.

\section{Discussion}


Tunable protein expression is crucial for synthetic and system biology. One of the powerful tools is the T7RNAP and its orthogonal T7 promoter. T7RNAP originating from the bacteriophage T7 elongates the RNA at a rate approximately 5 -fold faster than that of $E$. colinative RNA polymerase with specific recognition for the T7 promoter [34]. Therefore, the T7RNAP-mediated protein expression system was first applied in BL21(DE3) and showed that the chromosome-based $T 7$ gene 1 is more suitable for toxic gene expression from plasmids by preventing instability from the strong orthogonality of T7 system when compared to the plasmid-driven T7 gene 1 [35]. W3110 is one of the eminent E. coli strain and has been reported with high capability of withstanding different toxic chemicals [21-22]. Consequently, W3110 is a suitable strain to be equipped with the T7RNAP onto the chromosome. For examples, Liu and his colleagues has constructed the W3110(DE3), which entirely encompasses the same genetic design of BL21(DE3), to produce D-xylonic acid [36]. In this study, we provide three new W3110 strains equipped with different cassette of the T7RNAP as W3110::IL5, W3110::L5 and W3110::pl, which is achieved by the HK022 site-specific recombination, and displays its feasibility to produce heterologous protein and chemical production. Besides, the IPTG and lacO/lacl effect was further been elucidated.

From our results, W3110 showed a strong lac operon because the lacZ was overexpressed than that in BL21(DE3) when IPTG was expressed (Table 3), which was the first observation in our best knowledge. After addition of the T7RNAP cassette, the LacZ was further increased in expression, which was supposed that the partition of lacl from the lacZ to T7RNAP enhanced the lacZ expression. Lacl partition has already been proven to occur and applied in different applications. Cranenburgh and his coworkers developed a plasmid stabilization system, in which the plasmid containing multiple lacO sequence must be maintained in the cell to compete the lacl binding to prevent the binding to an essential gene [37]. On the other hand, in our design, the T7RNAP was immensely overexpressed in W3110 than that in BL21(DE3), which was elucidated by the insertion locus. Actually, the expression of insertion gene will be influenced by the surrounding DNA context which may contain a promoter, RBS or even a terminator to influence the down-stream gene expression [38]. In such context, it has been supposed that the wield behavior of W3110::IL5 with higher T7RNAP than that in W3110::L5 was also contributed by the surrounding DNA context to influence the lacl expression, which further affect the T7RNAP expression. Moreover, recently, the chromosome-base gene expression has been detailed elucidated in the aspect of the gene locus and it shown that the gene expression level must be determined by the easiness to relocate the gene to the nucleoid periphery [39], which further supported our explanation.

For the different proteins expression, by using a lacl/lac0 containing plasmid, it shows that all the expression could only occur as IPTG exists, while, as the plasmid without lacl/lac0 was utilized, the expression could both be observed in absence or presence of IPTG. Additional lacl in plasmid (i.e. pET plasmid, except for pET20b) could repress the T7RNAP expression tightly to reduce the leakage expression [6]. As the lacl/lacO was not encompassed in the plasmid (i.e. pSU or pET20b), the leakage expression is observed, but the protein expression with induction was still higher than that without induction in BL21(DE3), W3110::IL5 and W3110::L5, which is reasonable because the lacl on the chromosome could still sufficiently repress the $\mathrm{P}_{\text {LacUv } 5}$ with native lac RBS to express T7RNAP. 
Intriguingly, in pSU plasmid series, W3110::pl could express similar amount of heterologous protein with or without IPTG, which was attributed to the highly leakage level of T7RNAP. Actually, to establish a tightly regulated chromosome-based gene expression is intricate due to the difficulty to well-balance the promoter strength, lacl and lacO amount [40]. Besides, with the similar promoter strength of $\mathrm{P}_{\text {Lacl }}$ and $P_{\text {LacUv5 }}[6]$, the strength of RBS dominates the leakage expression of T7RNAP, where the B0034 RBS was extremely stronger than the lac native RBS (Fig. S4). The in vivo DAP production was also affected and displayed higher DAP yield in a short-term transformation (i.e. 6 and $12 \mathrm{~h}$ ) as the plasmid without $\mathrm{lacl} / \mathrm{lacO}$ was used, while the time used for highest production by plasmid with $\mathrm{lacl} / \mathrm{lacO}$ must be extended to $24 \mathrm{~h}$.

IPTG dose response is another point that have to be considered in an inducible system as PET with lad/laco was used [41]. In our results, W3110::IL5 must at least be induced by $0.1 \mathrm{mM}$ to obtain the enough recombinant protein, while W3110::L5 and W3110:pl only used $0.01 \mathrm{mM}$ to induce sufficient protein amount. Even with the similarly high expression of recombinant protein, the solubility would further affect the function of the recombinant protein [42], supporting the CA result where the optimal activity was occurred with $0.01 \mathrm{mM} \mathrm{IPTG}$ in the three engineered W3110 strains. Furthermore, the high orthogonality of T7 system was reported as an energy-intensive process [35], leading to less energy in folding the recombinant protein [43]. The in vivo production of DAP by W3110::pl harboring pSU-T7-CadA produced higher DAP without induction, primarily due to the cellular energy was more concentrated for lysine and DAP transportation as well as PLP regeneration [44-45].

\section{Conclusion}

In this study, the characterization of three engineered W3110-equipped with T7RNAP was accomplished as well as the difference of the lacl/ lacO regulation between W3110 and BL21(DE3) strains was proposed. Among all, the most robust one, W3110::pl strain with a T7RNAP driven by the promoter $\mathrm{P}_{\text {Lacl, }}$ enables effective, stable and constitutive production of several recombinant proteins and chemicals while strain W3110::L5 showed the similar capacity to produce the recombinant protein, but higher capacity to produce chemical as compared to the commercial BL21(DE3). Even though the W3110::IL5 does not behave efficiently as the other strains, it provides the new insights into the difference of Lac operon between $\mathrm{B}$ and $\mathrm{W}$ derivatives. Therefore, we not only provided a cost-effective, robust and novel engineered W3110 strain as a cell factory for recombinant technology, but also presented more understandings of different $E$. coli strains.

\section{Declarations}

\section{Acknowledgments}

The authors are grateful for financial support from the Ministry of Science and Technology (MOST 1082221-E-006-004-MY3, MOST 108-2218-E-006-006, and MOST 108-2621-M-006-015) in Taiwan. 


\section{Author contributions}

ISN and WWT conceived and designed research. WWT and SIT conducted experiments. ISN, WWT and SIT analyzed data and wrote the manuscript. All authors read and approved the manuscript.

\section{Ethics approval and consent to participate}

All of the authors have read and agreed to the ethics in publishing this manuscript.

\section{Consent for publication}

The authors provided consent for publishing this manuscript.

Competing interests: The authors declare that they have no competing interests.

Availability of data and material: We agree to the terms of the BioMed Central Copyright and License Agreement.

\section{References}

1. Gifre L, Arís A, Bach À, Garcia-Fruitós E. Trends in recombinant protein use in animal production. Microb Cell Fact. 2017;16:40.

2. Li Y, Cirino PC. Recent advances in engineering proteins for biocatalysis. Biotechnol Bioeng. 2014;111:1273-87.

3. Wu H, Fan Z, Jiang X, Chen J, Chen GQ. Enhanced production of polyhydroxybutyrate by multiple dividing E. coli. Microb Cell Fact. 2015;15:128-40.

4. Goeddel DV, Kleid DG, Bolivar F, Heyneker HL, Yansura DG, Crea R, Hirose T, Kraszewski A, Itakura K, Riggs AD. Expression in Escherichia coli of chemically synthesized genes for human insulin. Proc Natl Acad Sci USA. 1979;76:106-10.

5. Huang CJ, Lin H, Yang X. Industrial production of recombinant therapeutics in Escherichia coli and its recent advancements. J Ind Microbiol. 2012;39:383-99.

6. Rosano GL, Ceccarelli EA. Recombinant protein expression in Escherichia coli: advances and challenges. Front Microbiol. 2014;5:172.

7. Atsumi S, Cann AF, Connor MR, Shen CR, Smith KM, Brynildsen MP, Liao JC. Metabolic engineering of Escherichia coli for 1-butanol production. Metab Eng. 2008;10:305-11.

8. Jo M, Noh MH, Lim HG, Kang CW, Im DK, Oh MK, Jung GY. Precise tuning of the glyoxylate cycle in Escherichia coli for efficient tyrosine production from acetate. Microb Cell Fact. 2019;18:57.

9. Yuan SF, Alper HS. Metabolic engineering of microbial cell factories for production of nutraceuticals. Microb Cell Fact. 2019;18:46-61.

10. Datta S, Costantino N, Court DL. A set of recombineering plasmids for gram-negative bacteria. Gene. 2006;379:109-15. 
11. Studier FW, Moffatt BA. Use of bacteriophage T7 RNA polymerase to direct selective high-level expression of cloned genes. J Mol Biol. 1986;189:113-30.

12. Yu D, Ellis HM, Lee EC, Jenkins NA, Copeland NG. An efficient recombination system for chromosome engineering in Escherichia coli. Proc Natl Acad Sci USA. 2000;97:5978-83.

13. Chung ME, Yeh IH, Sung LY, Wu MY, Chao YP, Ng IS, Hu YC. Enhanced integration of large DNA into $E$. coli chromosome by CRISPR/Cas9. Biotechnol Bioeng. 2016;114:172-83.

14. Jiang W, Bikard D, Cox D, Zhang F, Marraffini LA. RNA-guided editing of bacterial genomes using CRISPR-Cas systems. Nat Biotechnol. 2013;31:233.

15. Ng IS, Hung YH, Kao PH, Zhou Y, Zhang X. CRISPR/Cas9 nuclease cleavage enables marker-free genome editing in Escherichia coli: A sequential study. J Taiwan Inst Chem E. 2016;68:31-9.

16. Zhao D, Yuan S, Xiong B, Sun H, Ye L, Li J, Zhang X, Bi C. Development of a fast and easy method for Escherichia coli genome editing with CRISPR/Cas9. Micro Cell Fact. 2016;15:205.

17. Grossman TH, Kawasaki ES, Punreddy SR, Osburne MS. Spontaneous cAMP-dependent derepression of gene expression in stationary phase plays a role in recombinant expression instability. Gene. 1998;209:95-103.

18. Lewis M, Chang G, Horton NC, Kercher MA, Pace HC, Schumacher MA, Brennan RG, Lu P. Crystal structure of the lactose operon repressor and its complexes with DNA and inducer. Science. 1996;271:1247-54.

19. Marbach A, Bettenbrock K. Lac operon induction in Escherichia coli: Systematic comparison of IPTG and TMG induction and influence of the transacetylase LacA. J Biotechnol. 2012;157:82-8.

20. Dvorak P, Chrast L, Nikel PI, Fedr R, Soucek K, Sedlackova M, Chaloupkova R, de Lorenzo V, Prokop Z, Damborsky J. Exacerbation of substrate toxicity by IPTG in Escherichia coli BL21(DE3) carrying a synthetic metabolic pathway. Microb Cell Fact. 2015;14:201.

21. Yoon SH, Han MJ, Jeong H, Lee CH, Xia XX, Lee DH, Shim JH, Lee SY, Kim JF. Comparative multiomics systems analysis of Escherichia coli strains B and K-12. Genome Biol. 2012;13:R37.

22. Fragoso-Jiménez JC, Baert J, Nguyen TM, Liu W, Sassi H, Goormaghtigh F, Melderen L, Gaytán P, Hernández-Chávez G, Martinez A, Delvigne F, Gosset G. Growth-dependent recombinant product formation kinetics can be reproduced through engineering of glucose transport and is prone to phenotypic heterogeneity. Microb Cell Fact. 2019;18:26.

23. Kang $\mathrm{D}, \mathrm{Kim} \mathrm{Y}, \mathrm{Cha} \mathrm{H}$. Comparison of green fluorescent protein expression in two industrial Escherichia coli strains, BL21 and W3110, under co-expression of bacterial hemoglobin. Appl Microbiol Biotechnol. 2002;59:523-8.

24. Huang JF, Liu ZQ, Jin LQ, Tang XL, Shen ZY, Yin HH, Zheng YG. Metabolic engineering of Escherichia coli for microbial production of L-methionine. Biotechnol Bioeng. 2017;114:843-51.

25. Li H, Wang BS, Li YR, Zhang L, Ding ZY, Gu ZH, Shi GY. Metabolic engineering of Escherichia coli W3110 for the production of I-methionine. J Ind Microbiol. 2017;44:75-88. 
26. Li H, Wang B, Zhu L, Cheng S, Li Y, Zhang L, Ding ZY, Gu ZH, Shi GY. Metabolic engineering of Escherichia coli W3110 for L-homoserine production. Process Biochem. 2016;51:1973-83.

27. Dong X, Chen X, Qian Y, Wang Y, Wang L, Qiao W, Liu L. Metabolic engineering of Escherichia coli W3110 to produce L-malate. Biotechnol Bioeng. 2017;114:656-64.

28. Haldimann A, Wanner BL. Conditional-replication, integration, excision, and retrieval plasmid-host systems for gene structure-function studies of bacteria. J Bacteriol. 2001;183:6384-93.

29. Chen PT, Chiang CJ, Wang JY, Lee MZ, Chao YP. Genomic engineering of Escherichia coli for production of intermediate metabolites in the aromatic pathway. J Taiwan Inst Chem E. 2011;42:3440.

30. Ng IS, Chen T, Lin R, Zhang X, Ni C, Shun D. Decolorization of textile azo dye and Congo red by an isolated strain of the dissimilatory manganese-reducing bacterium Shewanella xiamenensis BC01. Appl Microbiol Biotechnol. 2014;98:2297-308.

31. Kim YH, Kim HJ, Shin JH, Bhatia SK, Seo HM, Kim YG, Lee YK, Yang YH, Park K. Application of diethyl ethoxymethylenemalonate (DEEMM) derivatization for monitoring of lysine decarboxylase activity. $J$ Mol Catal B Enzym. 2015;115:151-4.

32. Hsu KP, Tan SI, Chiu CY, Chang YK, Ng IS. ARduino-pH Tracker and screening platform for characterization of recombinant carbonic anhydrase in Escherichia coli. Biotechnol Prog. 2019;35:e2834.

33. Qian ZG, Xia XX, Lee SY. Metabolic engineering of Escherichia coli for the production of cadaverine: a five carbon diamine. Biotechnol Bioeng. 2011;108:93-103.

34. Chamberlin M, Mcgrath J, Waskell L. New RNA polymerase from Escherichia coli infected with bacteriophage T7. Nature. 1970;228:227.

35. Tan SI, Ng IS. New Insight into plasmid-driven T7 RNA polymerase in Escherichia coli and use as a genetic amplifier for a biosensor. ACS Synth Biol. 2020;9:613-22.

36. Liu H, Valdehuesa KNG, Nisola GM, Ramos KRM, Chung WJ. High yield production of D-xylonic acid from D-xylose using engineered Escherichia coli. Bioresour Technol. 2012;115:244-8.

37. Cranenburgh RM, Lewis KS, Hanak JA. Effect of plasmid copy number and lac operator sequence on antibiotic-free plasmid selection by operator-repressor titration in Escherichia coli. J Mol Microbiol Biotechnol. 2004;7:197-203.

38. Rhodius VA, Mutalik VK, Gross CA. Predicting the strength of UP-elements and full-length $E$. coli $\sigma E$ promoters. Nucleic Acids Res. 2012;40:2907-24.

39. Yang S, Kim S, Kim DK, An HJ, Son JB, Gynnå AH, Lee NK. Transcription and translation contribute to gene locus relocation to the nucleoid periphery in E. coli. Nat Commun. 2019;10:1-12.

40. Schuller A, Cserjan-Puschmann M, Tauer C, Jarmer J, Wagenknecht M, Reinisch D, Grabherr R, Striedner G. Escherichia coli $\sigma 70$ promoters allow expression rate control at the cellular level in genome-integrated expression systems. Microb Cell Fact. 2020;19:1-11. 
41. Yi YC, Ng IS. Establishment of toolkit and T7RNA polymerase/promoter system in Shewanella oneidensis MR-1. J Taiwan Inst Chem Eng. 2020;109:8-14.

42. Tan SI, Ng IS, Yu YJ. Heterologous expression of an acidophilic multicopper oxidase in Escherichia coli and its applications in biorecovery of gold. Bioresour Bioprocess. 2017;4:1-10.

43. Baneyx F, Mujacic M. Recombinant protein folding and misfolding in Escherichia coli. Nat Biotechnol. 2004;22:1399-408.

44. Olughu W, Nienow A, Hewitt C, Rielly C. Scale-down studies for the scale-up of a recombinant Corynebacterium glutamicum fed-batch fermentation: loss of homogeneity leads to lower levels of cadaverine production. J Chem Technol Biotechnol. 2020;95:675-85.

45. Moon YM, Yang SY, Choi TR, Jung HR, Song HS, Han Yh, Park HY, Bhatia SK, Gurav R, Park K, Kim JS, Yang $\mathrm{YH}$. Enhanced production of cadaverine by the addition of hexadecyltrimethylammonium bromide to whole cell system with regeneration of pyridoxal-5'-phosphate and ATP. Enzyme Microb Technol. 2019;127:58-64.

\section{Figures}


(a)
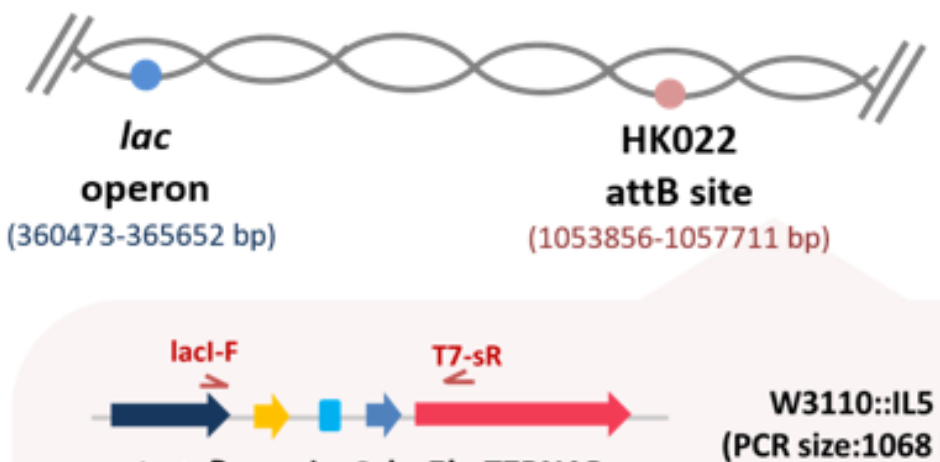

W3110::IL5

lacl $\mathbf{P}_{\text {Lacuvs }}$ laco lacz' T7RNAP

(PCR size:1068 bp)

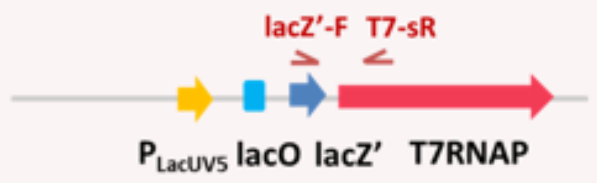

W3110::L5

(PCR size: 637 bp)

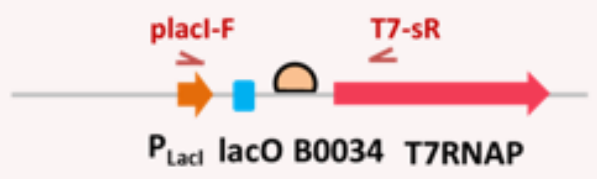

W3110::pl

(PCR size: 522 bp)

(b)

$\begin{array}{llll}M & 1 & 2 & 3\end{array}$

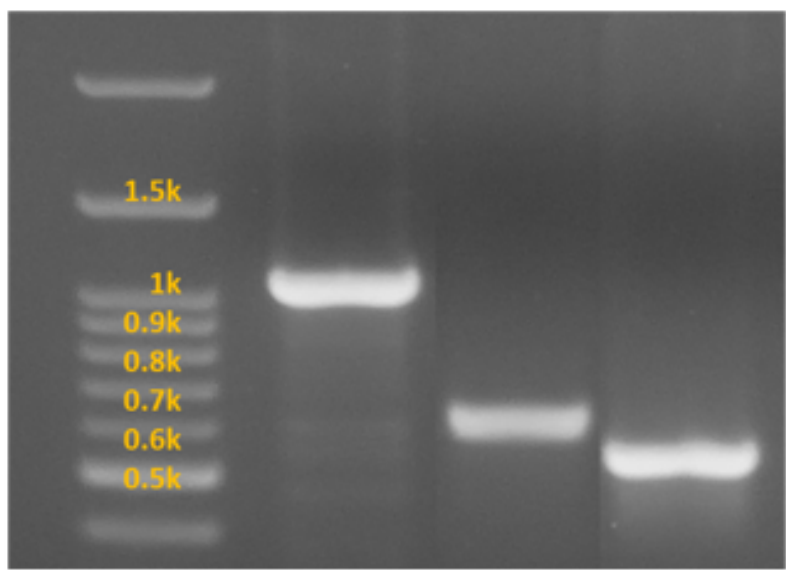

\section{Figure 1}

Scheme diagram of the engineered W3110 strain with chromosome-equipped T7RNAP (a) genetic design of engineered T7RNAP in E. coli W3110. Integration was achieved by site-specific recombination at the HK022 attB site. Three engineered T7RNAP expression strains were created. The strain W3110::IL5 has a lacl-PLacUV5-lacZ'-T7RNAP copy from BL21(DE3), and W3110::L5 lacks an additional integrated lacl. W3110::pl, in which T7RNAP is driven by the PLacl without additional repressor and lacZ' sequence near 
the promoter. The characteristic fragments of each strain were labeled by primers and result of confirmation was showed in (b): lane 1: PCR with primer lacl-F and T7-sR of W3110::IL5, lane 2: PCR with primer lacZ'-F and T7-sR of W3110::L5, lane 3: PCR with primer Placl-F and T7-sR of W3110::pl. The desired fragment of lacl-F and T7-sR is 1068 bp, lacZ'-F and T7-sR is 637 bp and 522 bp for Placl-F and T7-sR. M: 100 bp marker

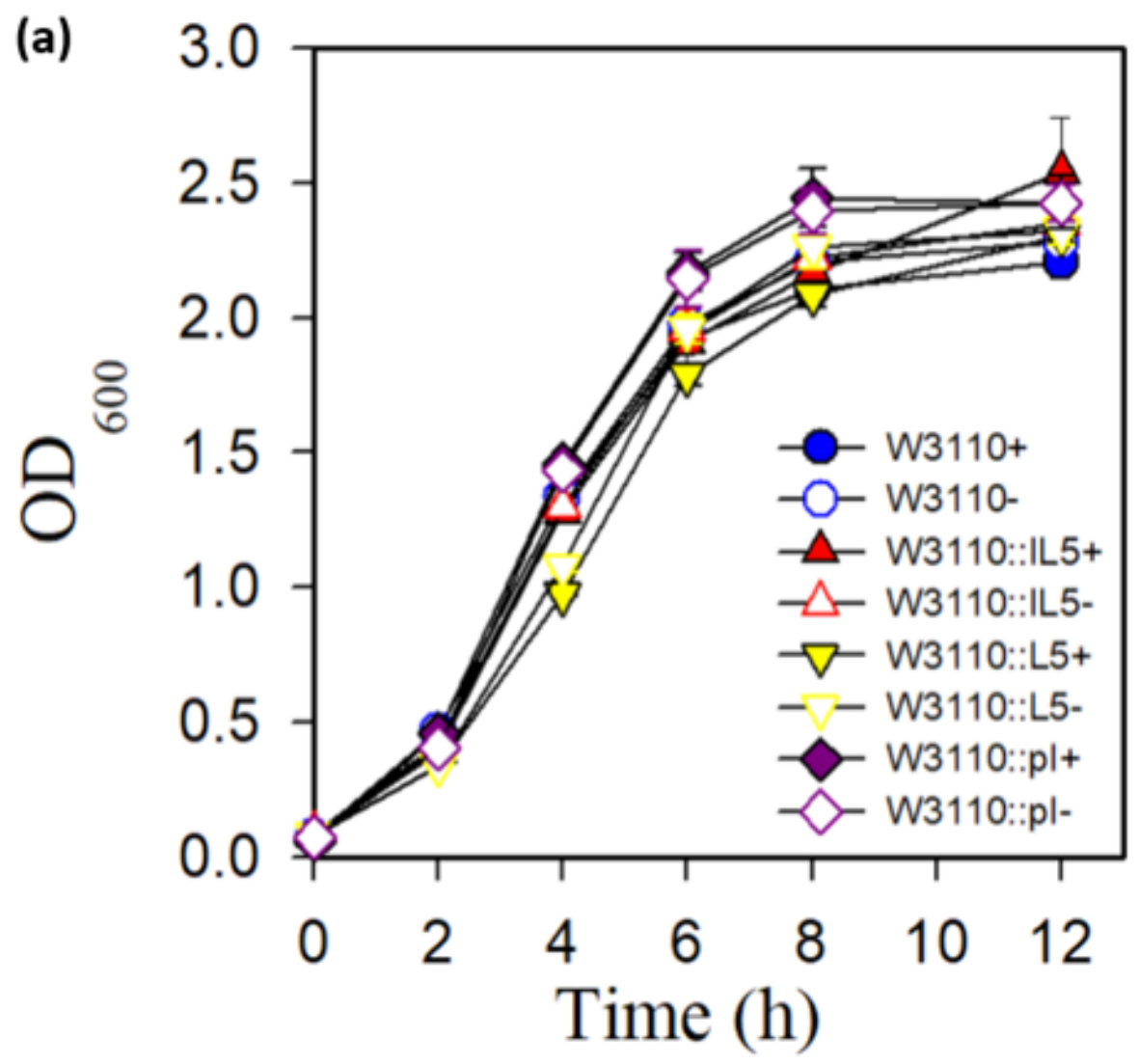

(b)

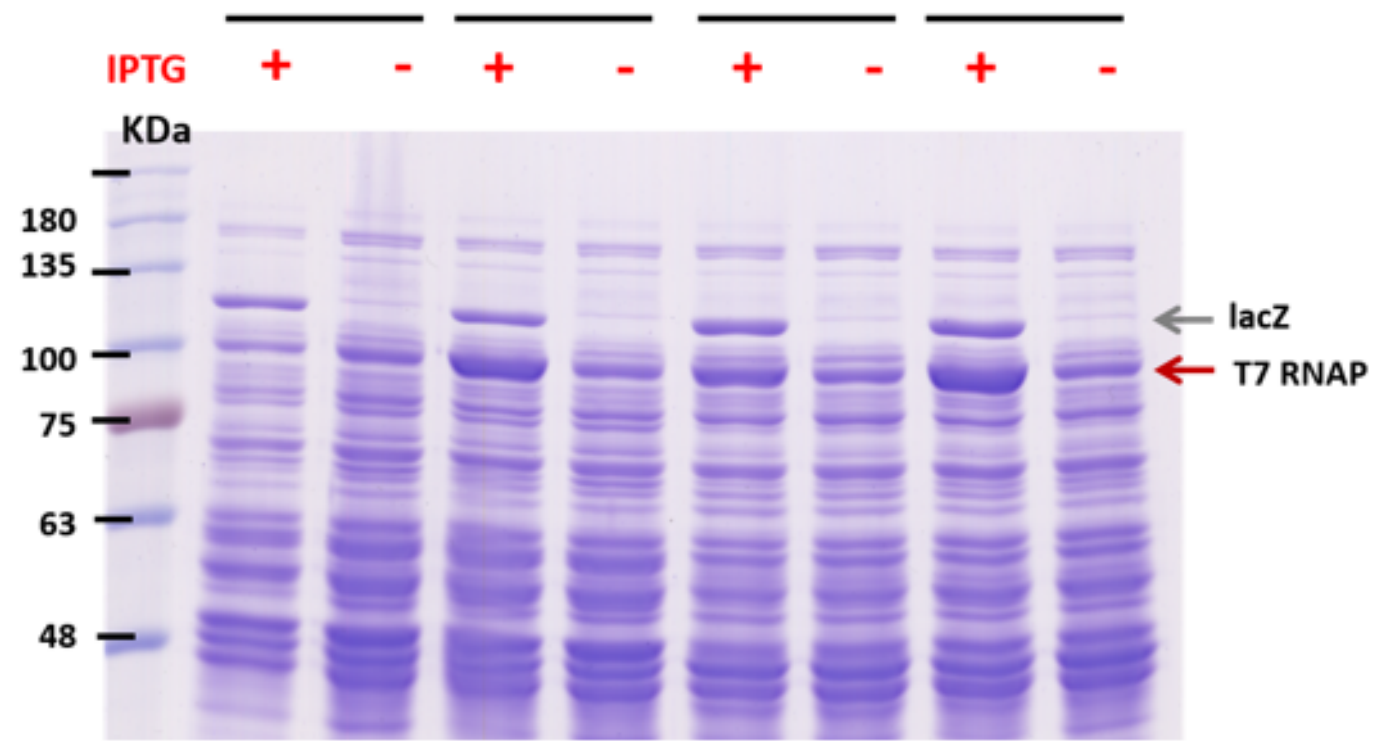

Figure 2 
Cell growth and protein expression analysis of four E. coli strains with and without induction by $0.1 \mathrm{mM}$ IPTG. (a) Cell growth and (b) SDS-PAGE for W3110, W3110::IL5, W3110::L5, and W3110::pl. The LacZ protein is approximately $116.4 \mathrm{kDa}$, as indicated by the gray arrow. The T7RNAP was approximately 98.8 $\mathrm{kDa}$, as indicated by the red arrow.

(a)

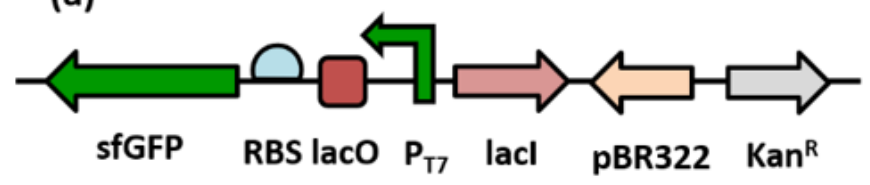

(c)

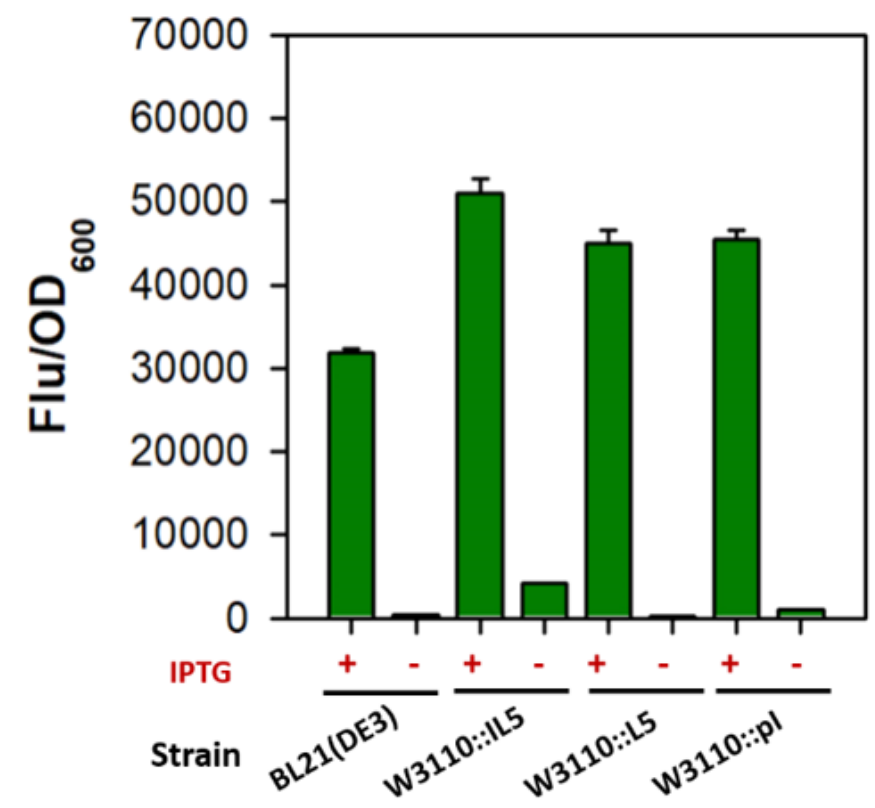

(b)

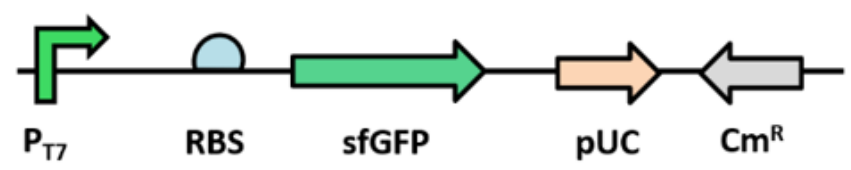

(d)

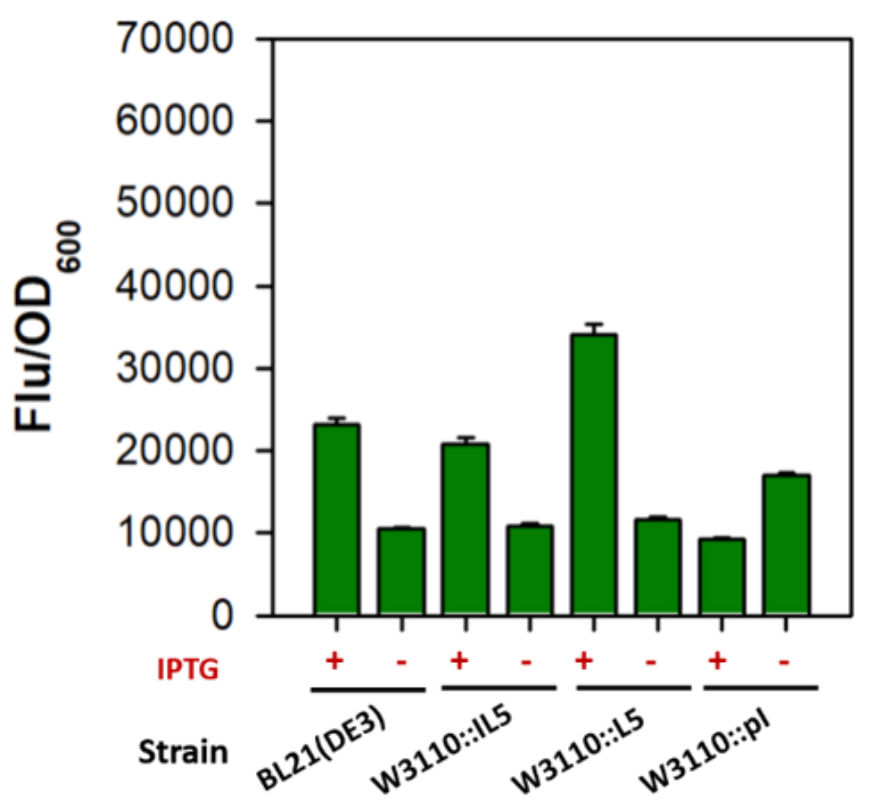

\section{Figure 3}

Comparison of sfGFP synthesis in the designed T7RNAP-carrying strains, with BL21(DE3) as a reference. sfGFP expressed from pET28a(+)-sfGFP plasmid (a) and pSU-T7-sfGFP plasmid (b). The fluorescence was analyzed by a microreader at $12 \mathrm{~h}$, with excitation and emission wavelengths of 480 and $510 \mathrm{~nm}$, respectively. (+) denotes IPTG induction and (-) denotes no IPTG induction.

(a)

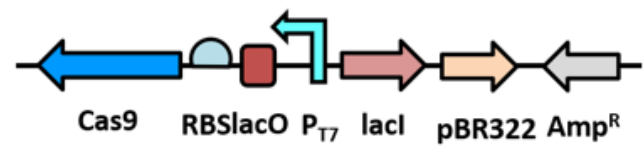

(c)

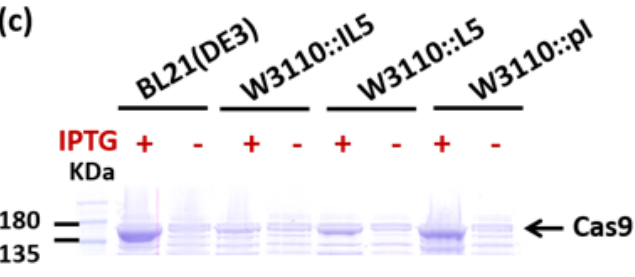

(b)

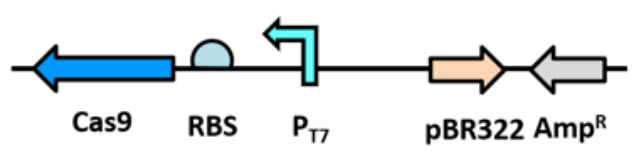

(d)

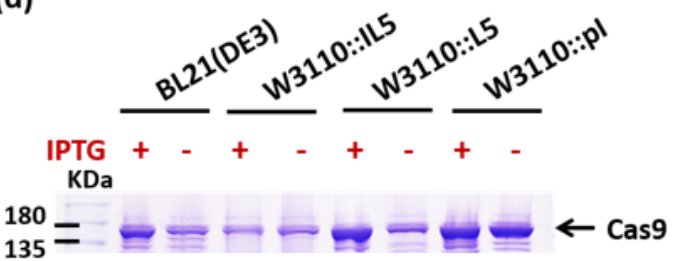

(e)

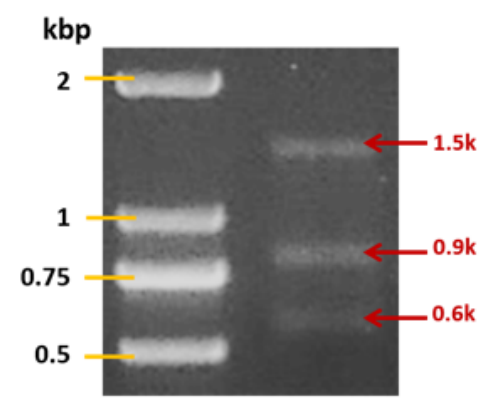


Figure 4

Functional Cas 9 protein expression in engineered W3110 strains with chromosome based T7RNAP and BL21(DE3) as a control. Cas9 protein expressed from inducible pET21a(+)-Cas9 plasmid (a) and constitutive pET20b-Cas9 plasmid (b). Results are shown in (c) for pET21a-Cas9, and (d) for pET20b(+)Cas9. The cells were harvested at $12 \mathrm{~h}$ after induction, and the whole cell protein expression of Cas 9 was analyzed by $8 \%(\mathrm{w} / \mathrm{v})$ SDS-PAGE. Cas9 has a size of $151.6 \mathrm{kDa}$, as indicated by the black arrow. (+) denotes IPTG induction and (-) denotes no IPTG induction. DNA gel results of an in vitro digestion assay with Cas9-RNP. The original size of the rbcL gene was $1.5 \mathrm{kbp}$, and the target site was designed to produce fragments of 0.6 and $0.9 \mathrm{kbp}$ after Cas9-RNP digestion (e).

(a)

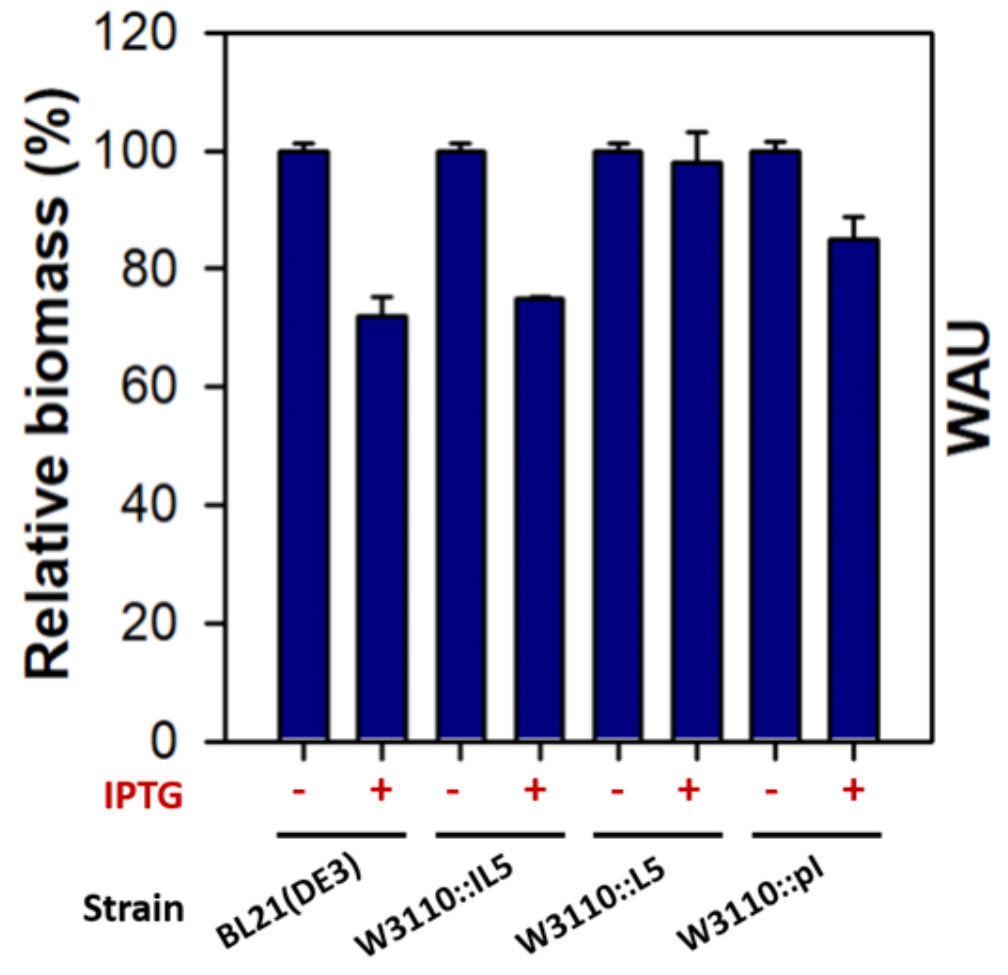

(b)

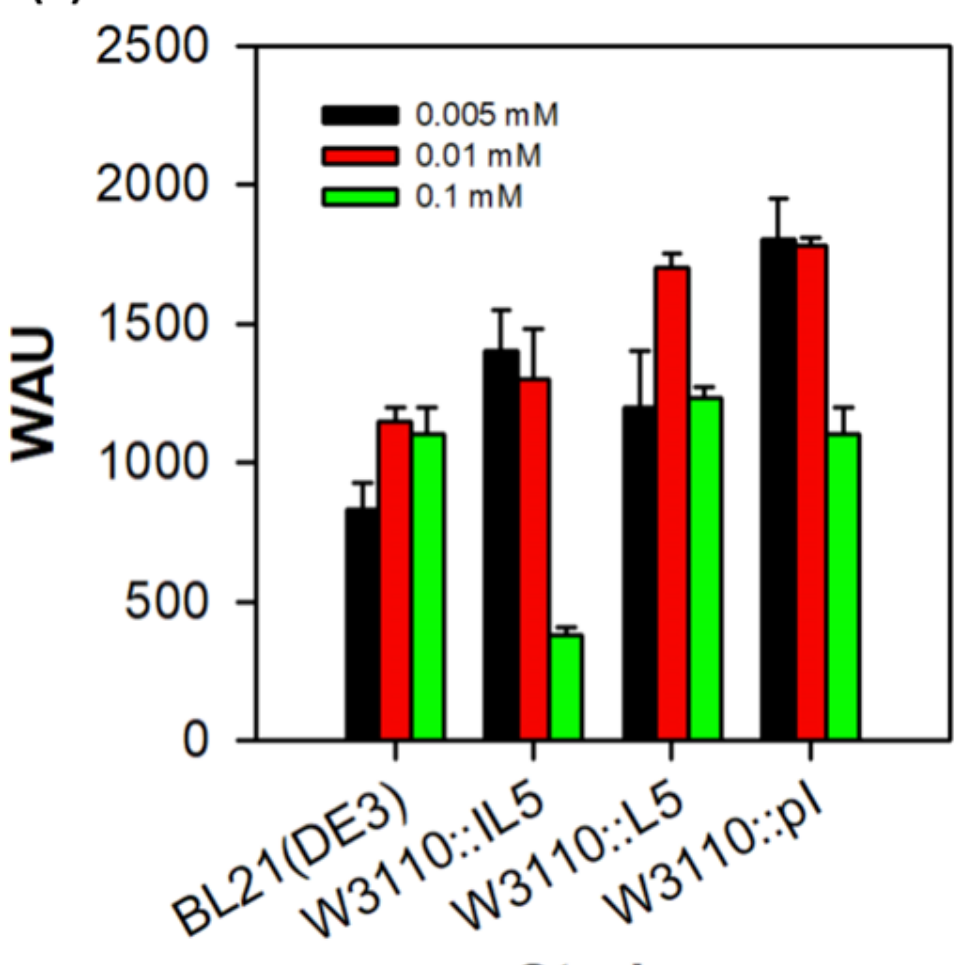

Strain

\section{Figure 5}

The cell biomass and enzyme activity of pET32a-SyCA in different engineered E. coli strains. (a) The relative biomass of different strains harboring pET32a-SyCA with or without $0.1 \mathrm{mM} \mathrm{IPTG}$ induction. (+) meant with IPTG and (-) meant without IPTG. Each strain without induction was chosen as standard respectively. (b) The activity of crude enzyme of pET32a-SyCA with $0.005,0.01,0.1 \mathrm{mM}$ IPTG in different strains determined by Wilbur-Anderson assay. 
(a)

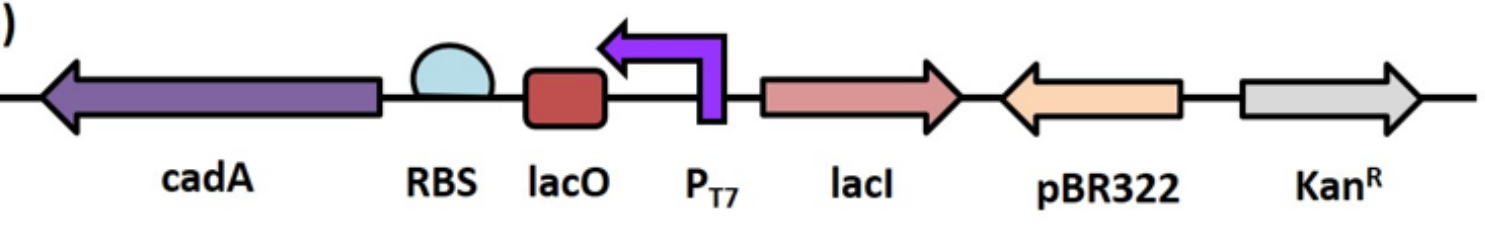

(b)
BL21(DE3)

IPTG
$(\mathrm{mM})$

0

KDa

KD

135

100

75

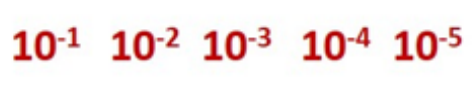

.

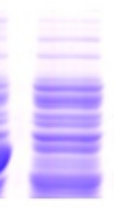

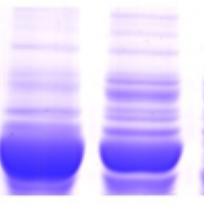

(d)

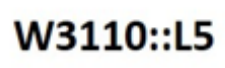

(c)

IPTG

$\begin{array}{lllllll}(\mathrm{mM}) \underset{\mathrm{KDa}}{\mathrm{M}} & 0 & 10^{-1} & 10^{-2} & 10^{-3} & 10^{-4} & 10^{-5}\end{array}$

W3110::IL5

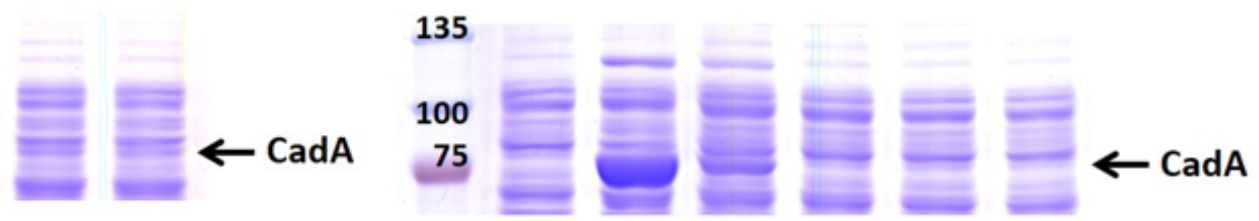

(e)

W3110::pl

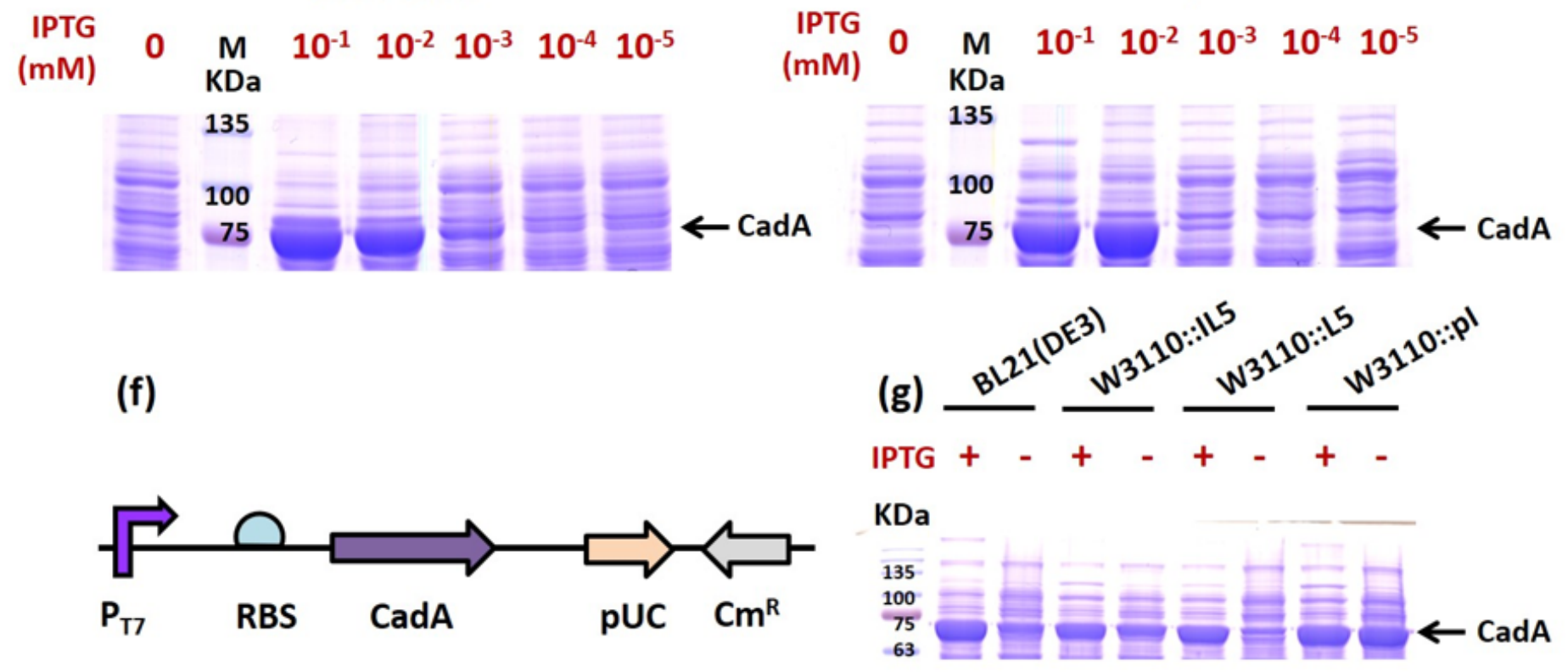

Figure 6

SDS-PAGE analysis of CadA protein expression from pET28a(+)-CadA plasmid (a) with $0,10-1,10-2,10-3$, 10-4 to 10-5 mM IPTG for the designed T7RNAP carrier strains. Results are shown for BL21(DE3) (b), W3110::L5 (c), W3110::IL5 (d), and W3110::pl (e). CadA protein expressed from pSU-T7-CadA plasmid (f). Whole cell protein expression of CadA from pSU-T7-CadA in different strains with or without $0.1 \mathrm{mM} \mathrm{IPTG}$ was analyzed by $8 \%(\mathrm{w} / \mathrm{v})$ SDS-PAGE (g). CadA has a size of $78.76 \mathrm{kDa}$, as indicated by the purple arrow. (+) denotes IPTG induction and (-) denotes no IPTG induction.

\section{Supplementary Files}

This is a list of supplementary files associated with this preprint. Click to download. 
- 2020W3110supporting.docx

Page 26/26 